\title{
Influence of salinity and moisture on the threshold shear velocity of saline sand in the Qarhan Desert, Qaidam Basin of China: A wind tunnel experiment
}

\author{
LI Chao, DONG Zhibao, YIN Shuyan*, CHEN Guoxiang, YANG Junhuai \\ College of Geography and Tourism, Shaanxi Normal University, Xi'an 710119, China
}

\begin{abstract}
Determination of the threshold shear velocity is essential for predicting sand transport, dust release and desertification. In this study, a wind tunnel experiment was conducted to evaluate the influence of salinity and moisture on the threshold shear velocity of saline sand. Saline sand samples (mean particle size of 164.50 $186.08 \mu \mathrm{m}$ and the total silt, clay and salt content of $0.80 \%-8.25 \%$ ) were collected from three saline sand dunes (one barchan dune and two linear dunes) in the Qarhan Desert, Qaidam Basin of China. Original saline sand samples were placed in two experimental trays for wet and dry processing to simulate deliquescence and desiccation, respectively. Surface moisture content ranging from $0.30 \%$ to $1.90 \%$ was generated by the steam method so that the saline sand can absorb water in a saturated water vapor environment. The motion of sand particles was determined by the observers with a solid laser. The laser sheet $(0.80 \mathrm{~cm}$ thick), which was emitted by the solid laser, horizontally covered the sand surface and was bound to the sand. Results show that the cohesion of saline sand results from a combination of salt and water. The threshold shear velocity increases exponentially with the increase in crust thickness for the linear sand dunes. There is a positive linear correlation between the original moisture content and relative threshold shear velocity. The threshold shear velocity of dewatered sand is greater than that of wet sand with the same original moisture content. Our results will provide valuable information about the sand transport of highly saline soil in the desert.
\end{abstract}

Keywords: threshold shear velocity; saline sand; barchan dune; linear dune; crust thickness; moisture content; Qaidam Basin

Citation: LI Chao, DONG Zhibao, YIN Shuyan, CHEN Guoxiang, YANG Junhuai. 2019. Influence of salinity and moisture on the threshold shear velocity of saline sand in the Qarhan Desert, Qaidam Basin of China: A wind tunnel experiment. Journal of Arid Land, 11(5): 674-684. https://doi.org/10.1007/s40333-019-0058-x

\section{Introduction}

The widespread salt crust in Qaidam Basin acts as armor for the landscape and protects the underlying material from erosion (Rohrmann et al., 2013). The resulting reduction in dust and sand entrainment and transport affects the atmosphere and marine plankton in eastern Asia (Zhang et al., 2003; Pullen et al., 2011; Rohrmann et al., 2013).

The determination of threshold shear velocity, i.e., the wind velocity at which aeolian sand transport begins to occur, is necessary for predicting the total sand flux and associated dust entrainment (Martin and Kok, 2017). Since the seminal work of Bagnold (1941), two types of threshold shear velocity have been defined: the fluid threshold for initiating saltation and the impact threshold for sustaining it. The initiation of motion of unconsolidated sand particles on a

\footnotetext{
*Corresponding author: YIN Shuyan (E-mail: yinshy@snnu.edu.cn)

Received 2018-04-18; revised 2018-08-08; accepted 2018-09-20

C Xinjiang Institute of Ecology and Geography, Chinese Academy of Sciences, Science Press and Springer-Verlag GmbH Germany, part of Springer Nature 2019
} 
dry, horizontal surface largely depends on grain diameter and the square root of the Shields parameter (expressed as the constant A, a proportionality coefficient which depends on the particle friction Reynolds number) (Bagnold, 1941; Ellis and Sherman, 2013). However, interparticle cohesive forces should also be considered when granular particles such as dust and sand are brought into contact, including van der Waals forces, water adsorption forces and electrostatic forces (Namikas and Shennan, 1995; Castellanos, 2005; Kok et al., 2012; Raffaele et al., 2016). Moreover, natural sand always (more or less) consists of particles with different sizes. Therefore, the fluid boundary is random (Zimon, 1982; Nickling, 1988; Nickling and Neuman, 2009). And, the threshold shear velocity cannot be given a single value but should be viewed as a threshold range which is a function of the size, shape, sorting and packing of the surface sediment (Nickling, 1988; Williams et al., 1990).

Threshold shear velocity is a property of the sediment surface, rather than of a single particle. It describes the capacity of the surface to resist wind erosion and is influenced by many factors, such as soil surface moisture content, crusting, roughness and biomass cover (Shao and Lu, 2000; Ishizuka et al., 2008; Shao, 2008; Zhang et al., 2008; Brungard et al., 2015; Xi and Sokolik, 2015; Zhang et al., 2016). Surfaces that are wet, rough, aggregated, crusted and partially covered with crop residue generally have a higher threshold shear velocity than surfaces that are dry, smooth, single-grained, non-crusted and devoid of vegetation (Ravi et al., 2006; Davidson-Arnott et al., 2008; Ishizuka et al., 2008; Sharratt and Vaddella, 2014; Raffaele et al., 2018). Natural surface crust can significantly reduce dust emission and soil erosion (Chepil, 1958; Zobeck, 1991; Zhang et al., 2008; Yan et al., 2015; Nield et al., 2016). In nature, an exposed soil surface usually forms a crust after cycles of saturation and insolation (Chen et al., 1980; Gomes et al., 2003). Saturation is caused by precipitation, condensation and capillary action; and drying is caused by evaporation due to solar radiation and wind. Subsequently, the soil becomes compacted and its shear strength will increase even if it does not contain salt. Many field investigations have shown that the threshold shear velocity of crusted soil can be $8.00 \%-270.00 \%$ greater than that of uncompacted soil (Gillette et al., 1982; Belnap and Gillette, 1998; Leys and Eldridge, 1998; Argaman et al., 2006).

In arid and semi-arid areas, the disintegrated crust (solonchak) on playas, gravel desert, sandy desert, grassland and severely salinized farmland is a significant source of airborne dust particles. In some inland lakes in arid areas, such as the Aral Sea, further desiccation has led to dust storms evolving into salt storms (Orlovsky et al., 2003). Widely dispersed beach sand can be affected by sea salt, resulting in the increase of its cohesion (Pye, 1980). However, the research about the effects of soluble salts on erosion and deflation is limited (Nickling and Ecclestone, 1981; Nickling, 1984; Wang et al., 2013; Nield et al., 2016). Detailed wind tunnel experiments have shown that threshold shear velocity is very sensitive to salt content, and that even a low salt concentration can significantly increase its value. The relationship between salinity and threshold shear velocity can be represented by exponential functions. Salt crystals are formed by desiccation and enveloped by small sediment particles, filling the interstices between sand grains. The salt has a cementation effect and can bind sand grains, thus changing the surface structure of the sediment and significantly increasing its stability (Nickling and Ecclestone, 1981; Nickling, 1984). In the playa basin, dust emission from salt crusted surfaces can also occur without saltation. Disturbance or destruction of the salt crust can reduce the wind speed threshold of dust emission and increase the release of dust (Nield et al., 2016). In Qaidam Basin, saline sediment influences dune evolution and alters sand dune morphology (Rubin and Hesp, 2009; Wolfe and Hugenholtz, 2009; Rubin and Rubin, 2013; Dong et al., 2017; Xiao et al., 2017; Zhang et al., 2018). Although, there has been much research on the sediment and dune composition, wind conditions, dune patterns and the temporal aspects of dune formation (Rubin and Hesp, 2009; Zhou et al., 2012; Li et al., 2015, 2016; Zhang et al., 2018). The understanding of how salt and clay affect sediment transport and the formation of linear dunes is still not clear.

The objective of this study is to assess the influence of deliquescence and desiccation on the initiation of particle motion in saline sand dunes. Quantifying the effect of cohesion on limiting sediment deflation can provide valuable information about the sand transport of highly saline 
soils.

\section{Materials and methods}

\subsection{Test dune sand}

Samples of three different types of sand were collected from the upper-middle part of sand dunes (1-5 cm deep) in the northern Qarhan Desert, Qaidam Basin of China in 2017. The first kind of sand was from the barchan dune $\left(37^{\circ} 09^{\prime} 31^{\prime \prime} \mathrm{N}, 9^{\circ} 12^{\prime} 33^{\prime \prime} \mathrm{E}\right.$; Fig. 1a) and the other two were from the linear dunes (linear dune 1: $37^{\circ} 07^{\prime} 22^{\prime \prime} \mathrm{N}, 9^{\circ} 18^{\prime} 20^{\prime \prime} \mathrm{E}$ and linear dune 2: $37^{\circ} 05^{\prime} 39^{\prime \prime} \mathrm{N}$, $95^{\circ} 25^{\prime} 33^{\prime \prime E}$; Fig. 1b). Each sand sample was sealed in situ. A piece of salt crust was collected on the surface of linear dune 2 (kept in a sealed glass bottle).

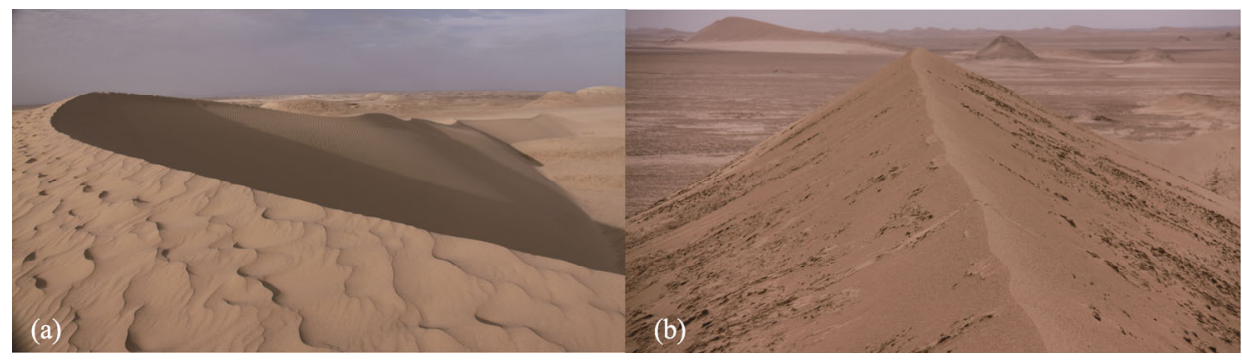

Fig. 1 Dune sediment of the barchan dune (a) and linear dune (b)

Three groups of samples were selected from each kind of dune sand for salinity and granularity measurement. Salinity of the samples was measured by evaporation of distilled water (salt content=mass of dried residue) and granularity was measured by a Mastersizer 2000 laser diffraction particle size analyser (Malvern Instruments Inc., UK). Figure 2 shows the particle size distribution and Table 1 shows the graphical statistical indicators of the sand samples. The mean particle size of samples from the three sand dunes was from 175.04 to $228.91 \mu \mathrm{m}$ (Table 1). The sands were mostly medium sand proportion (mean 56.63\%). All the sands were moderately well sorted and normally distributed. The sand proportion in the linear dune 2 was approximately $20.00 \%$ smaller than those in the other two dunes. The total silt, clay and salt (TSCS) content reflected the content of cohesive sediment in the sand dune (Zhou et al., 2012). TSCS content of the barchan dune was significantly lower than those of the linear dunes (Table 2). Bao (2016) pointed out that soluble salts are principally chloride salts around the Qarhan Salt Lake in the Qaidam Basin. The cations are mainly $\mathrm{Na}^{+}$and contain small amounts of $\mathrm{Ca}^{2+}$ and $\mathrm{K}^{+}$, while the anions are mainly $\mathrm{Cl}^{-}$and contain small amounts of $\mathrm{SO}_{4}{ }^{2-}$ and $\mathrm{CO}_{3}{ }^{2-}$.

In order to provide a comparison between wet and dry sediment behaviour, we prepared two experimental trays for each sand dune. The experimental tray is specially reinforced to prevent the crust from being damaged by slight bending. Detailed preparation of the experimental sand surfaces can be described as the following steps. Specifically, two experimental trays $(0.50$ $\mathrm{m} \times 0.40 \mathrm{~m} \times 0.02 \mathrm{~m}$ ) full of saline sand from the same sample were dried at $105^{\circ} \mathrm{C}$ for $8 \mathrm{~h}$ to ensure the sands were fully dry. To reduce the influence of temperature on water absorption of sand, we cooled the dried sand to room temperature in a drying vessel. The humidification process was done in a clear acrylic box $(1.00 \mathrm{~m} \times 1.00 \mathrm{~m} \times 0.75 \mathrm{~m})$ by the steam method. The saline sand samples in the trays were moistened in a saturated water vapor environment provided by a humidifier and the moisture content of the sands was controlled by humidification time. Surface moisture content ranged from $0.30 \%$ to $1.90 \%$. Original moisture content was measured by scraping a 1-mm layer from the top of saline sand sample using a specially designed metal sheet, and then oven-drying and weighing. One of the two moistened experimental trays was placed in the oven to dry again $\left(105^{\circ} \mathrm{C}\right.$ for $\left.8 \mathrm{~h}\right)$ and then cooled to room temperature in a drying vessel, and the other tray was directly used to test the threshold shear velocity. The process of humidification and drying simulated deliquescence and desiccation of saline sand surfaces in the natural 
environment, respectively. Wet sand represented the saline sand after water absorption from the air and dewatered sand represented the air-dried saline sand which usually formed crusts.

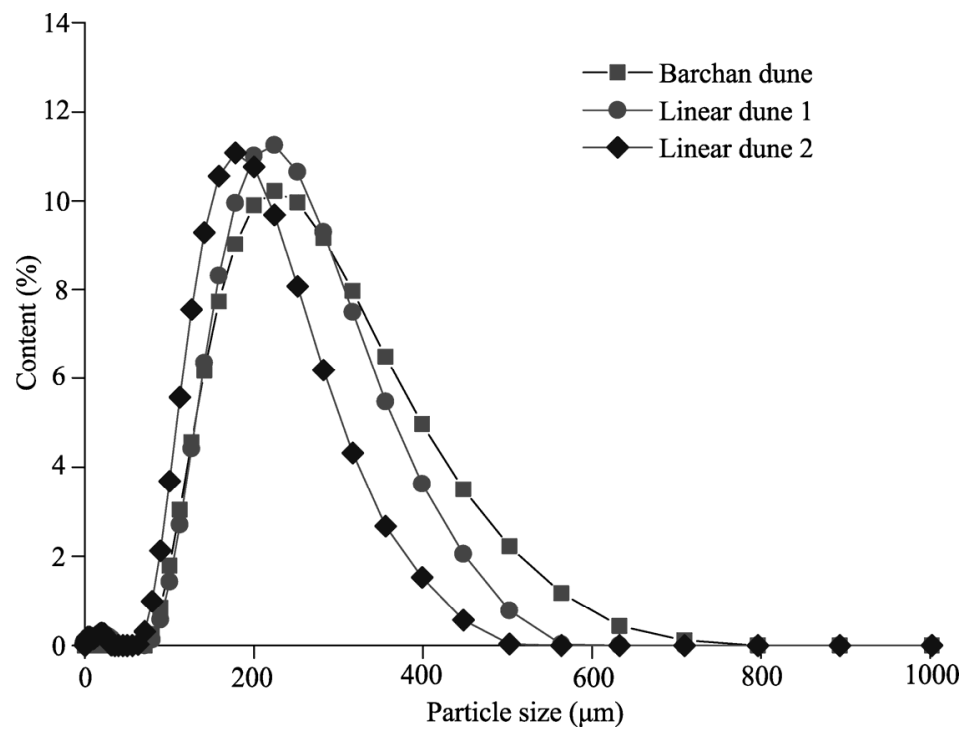

Fig. 2 Particle size distribution of saline sand samples in different sand dunes

Table 1 Particle size distribution of saline sand samples in different sand dunes using the Udden-Wentworth scale (Udden, 1914; Wentworth, 1922) and graphical statistical indicators (Folk and Ward, 1957)

\begin{tabular}{|c|c|c|c|c|c|c|}
\hline \multirow{3}{*}{ Sand dune } & \multicolumn{6}{|c|}{ Particle size distribution of saline sand (\%) } \\
\hline & Very coarse sand & Coarse sand & Medium sand & Fine sand & Very fine sand & Silt \\
\hline & $500-1000(\mu \mathrm{m})$ & $250-500(\mu \mathrm{m})$ & $125-250(\mu \mathrm{m})$ & $63-125(\mu \mathrm{m})$ & $31-63(\mu \mathrm{m})$ & $<31(\mu \mathrm{m})$ \\
\hline Barchan dune & 1.79 & 34.85 & 52.85 & 10.03 & 0.00 & 0.48 \\
\hline Linear dune 1 & 0.03 & 29.33 & 57.33 & 8.81 & 0.06 & 4.44 \\
\hline Linear dune 2 & 0.00 & 15.74 & 59.70 & 19.54 & 0.02 & 5.00 \\
\hline \multirow{2}{*}{ Sand dune } & \multicolumn{6}{|c|}{ Graphical statistical indicator } \\
\hline & $M_{z}(\mu \mathrm{m})$ & $\sigma$ & $S_{k}$ & $K_{G}$ & & \\
\hline Barchan dune & 228.91 & 0.62 & 0.00 & 0.95 & & \\
\hline Linear dune 1 & 210.01 & 0.61 & 0.10 & 1.08 & & \\
\hline Linear dune 2 & 175.04 & 0.82 & 0.25 & 1.76 & & \\
\hline
\end{tabular}

Note: $M_{z}$, the mean particle size; $\sigma$, the sorting coefficient; $S_{k}$, the skewness; $K_{G}$, the kurtosis.

Table 2 Contents of sand and TSCS in saline sand samples of different sand dunes

\begin{tabular}{ccccc}
\hline Sand dune & Sand (\%) & Silt and clay (\%) & Salt (\%) & TSCS (\%) \\
\hline Barchan dune & 99.20 & 0.48 & 0.32 & 0.80 \\
Linear dune 1 & 93.33 & 4.39 & 2.28 & 6.67 \\
Linear dune 2 & 91.75 & 4.85 & 3.40 & 8.25 \\
\hline
\end{tabular}

Note: TSCS, total silt, clay and salt.

\subsection{Instrumentation}

We took a scanning electron micrograph with Hitachi S-3400N (Hitachi Inc., Japan) at a magnification of 100 times to observe the details of the salt crust. The wind tunnel experiment was carried out at the Aeolian Process Dynamics Laboratory of Shaanxi Normal University, China. The experimental apparatuses are shown in Figure 3. The indoor open-circuit blower wind tunnel was $16.50 \mathrm{~m}$ long, and the length of working section was $7.00 \mathrm{~m}$ with a cross-section of $0.50 \mathrm{~m}$ width and $0.60 \mathrm{~m}$ height. The wind velocity along the central axis of the wind tunnel could be set in the range from 3 to $35 \mathrm{~m} / \mathrm{s}$. A $0.50 \mathrm{~m} \times 1.00 \mathrm{~m}$ roughness element (a turbulence generator made up of small wood rods perpendicular to the wind tunnel floor) was located at the entrance of 
the test section. The boundary layer in the test section can be at a height of $>0.12 \mathrm{~m}$. When the free-stream wind velocity was $6 \mathrm{~m} / \mathrm{s}$, the Reynolds number was $6.28 \times 10^{4}$. Wind profiles were measured by a wind profiler consisting of 5 ruggedized constant temperature anemometer probes (at heights of 1, 2, 5, 15 and $30 \mathrm{~cm}$ above the wind tunnel floor) which were $5.90 \mathrm{~m}$ downwind from the entrance of the test section connected to a data logger. Data acquisition frequency of the wind profiler was $1 \mathrm{~Hz}$. The sample tray (full of saline sand), which was placed on a variable-height platform $(0.30 \mathrm{~m} \times 0.30 \mathrm{~m})$, was $5.30 \mathrm{~m}$ downwind from the entrance of the test section. It should be noted that the surface of the tray was level with the wind tunnel floor. The reflector of solid-state laser was $1.50 \mathrm{~m}$ from the adjacent wind tunnel wall. The solid-state laser emitted a green laser sheet $(0.80 \mathrm{~cm}$ thick) which horizontally covered the sand surface and was bound to the sand. The wind tunnel wall was covered by an opaque baffle to reduce light diffraction and control the range of laser exposure.

(a)
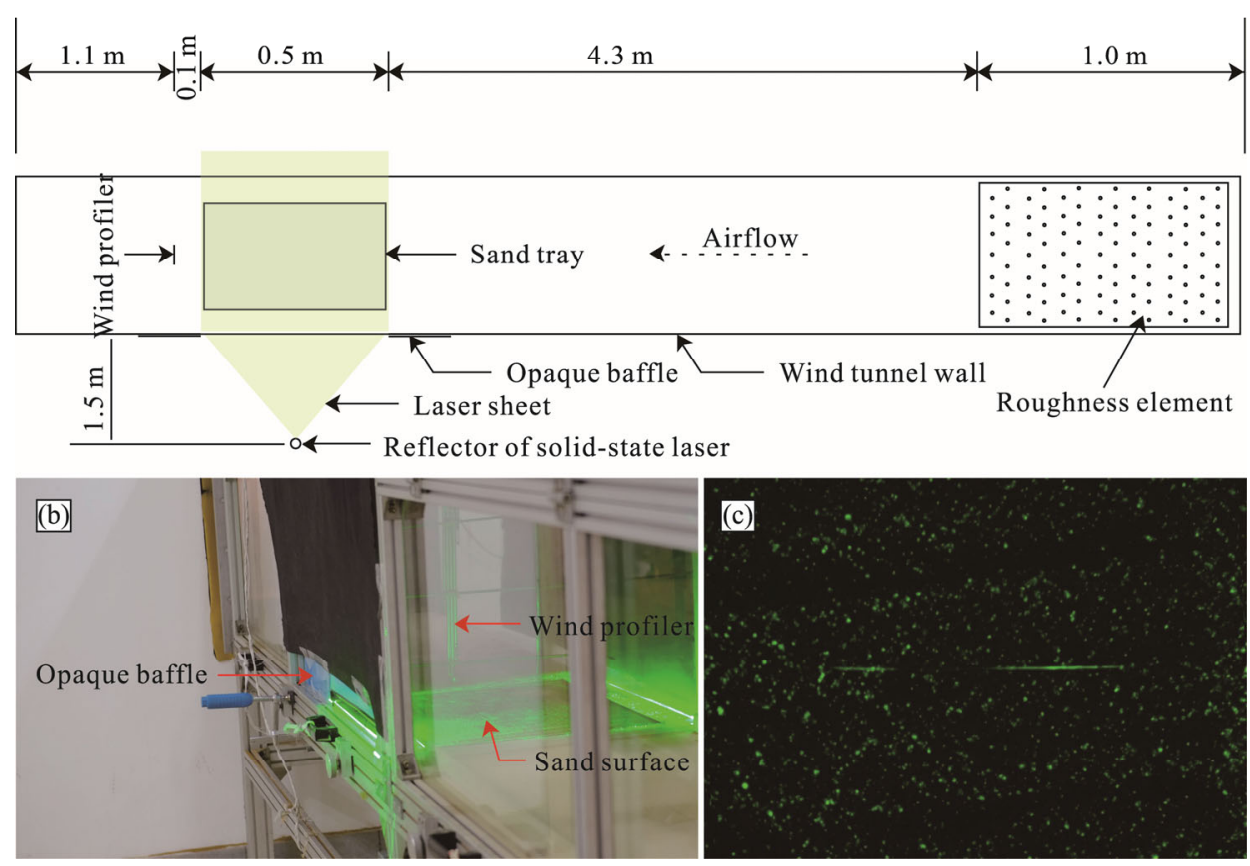

Fig. 3 Top view showing the layout of the wind tunnel floor (a), setup of the sand tray and wind profiler in the wind tunnel (b) and sand motion captured by the camera (c)

\subsection{Experimental procedure}

The wind tunnel experiments were conducted in the dark. Wind velocity was gradually increased until sand particle motion was initiated. The inverter started at $5 \mathrm{~Hz}$ (the corresponding wind velocity at the entrance of the wind tunnel was approximately $3 \mathrm{~m} / \mathrm{s}$ ) and increased at an increasing rate of $0.20 \mathrm{~Hz} / \mathrm{s}$. Three observers visually determined the start of the sand particle motion following a procedure used by previous researchers (Musick et al., 1996; Dong et al., 2002). The moving particles were lighted up by the laser and were easily recognized by the observers. The wind profile was recorded and the wind tunnel was returned to its initial state. Firstly, the threshold shear velocity of dried loose sand $\left(u_{*_{t o}}\right)$ was measured. Then, the threshold shear velocity of processed (wet or dewatered) sand $\left(u_{* t r}\right)$ was measured. This procedure was repeated 6 times to determine the sand particle fluid threshold within a small range. Since some surface particles may be in a mechanically unstable position as a result of the preparation of the sand (Nickling, 1988), we determined the value of the threshold shear velocity based on the mean value of the last three results. The thicknesses of 5 pieces of dry sand crust were measured with a vernier caliper (Fig. 4). Most of the tests were completed within 3 min. 


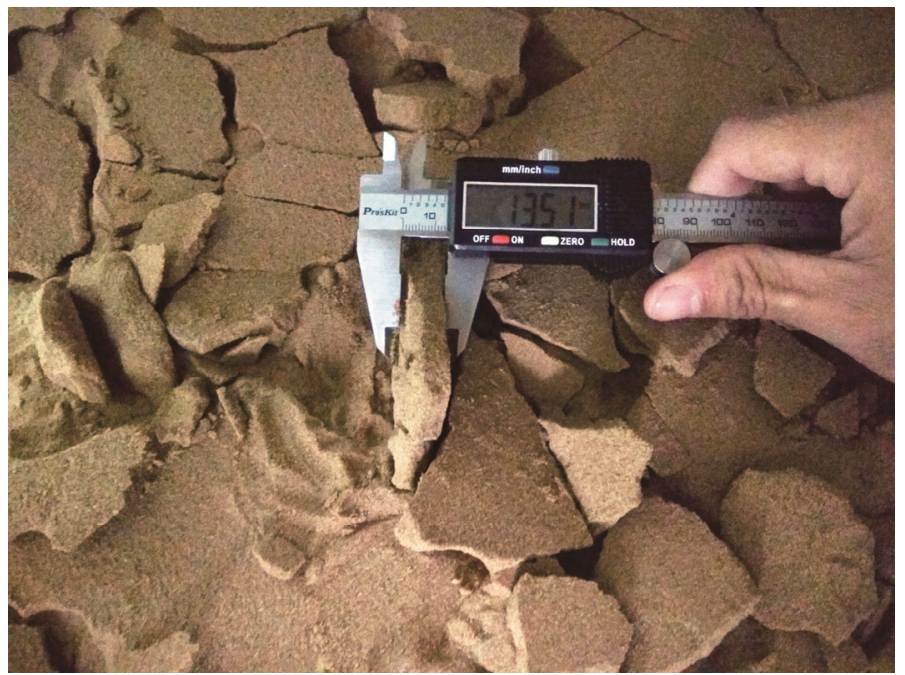

Fig. 4 Measuring the thickness of dry sand crust using a vernier caliper

\subsection{Shear velocity calculation}

The least squares method of curve fitting was used to calculate the shear velocity (Wilkinson, 1983, Sherman et al., 1998; Dong et al., 2004). Wind velocity can be calculated as a function of height by the following equation:

$$
U_{z}=\mathrm{a}+\mathrm{b} \times \ln z,
$$

where $U_{z}$ is the wind velocity at the height $z(\mathrm{~m} / \mathrm{s}) ; z$ is the height $(\mathrm{m})$; and a and $\mathrm{b}$ are the regression coefficients. The shear velocity was calculated as Equation 2.

$$
u_{*}=\mathrm{k} \times \mathrm{b} \text {, }
$$

where $u_{*}$ represents the measured threshold shear velocity $\left(u_{*_{t}}\right)$ for the initiation of particle motion $(\mathrm{m} / \mathrm{s}) ; \mathrm{k}$ is the von Kármán constant $(0.40)$; and $\mathrm{b}$ is the regression coefficient from Equation 1.

\subsection{Data analysis}

Regressions analysis was used to determine the relationship among the variables including the original moisture content, crust thickness, threshold shear velocity and relative threshold shear velocity. Goodness-of-fit and significance test of the regression equations were used to facilitate the understanding of controlling factors of particle motion. Variables were considered to be significantly correlated at or above the $95 \%$ confidence level $(P \leq 0.05)$. Homoscedasticity was used to determine the homogeneity of data. Significant correlation at $P>0.05$ level was defined as homoscedasticity in the Levene statistic.

\section{Results and discussion}

\subsection{Threshold shear velocity and crust properties}

In the experiment, we found that the dewatered saline sand collected from the linear dunes formed cemented surface layer or crust, and the thickness of the surface layer or crust increased as the original moisture content increased (Fig. 5a). However, for the barchan dune, a very thin crust $(<1.00 \mathrm{~mm})$ was formed merely at a relatively high moisture content (approximately $1.50 \%)$. For the saline sand, the thickness of the crust was determined by the TSCS content and moisture content. The water absorption of saline sand mainly depended on the salt content because the salt has the feature of deliquescence. The silt and clay filled the voids between the sand grains and increased the strength of crust. As shown in Figure 5b, particles of dried saline sand naturally cemented by a mixture of salt crystals and clay. The results are consistent with the observations in the field. The linear dunes in the Qarhan Desert were mostly covered with thick crust, and only 
the crest was covered with loose sand. However, the sand of the barchan dune was loose. The threshold shear velocity increased exponentially with crust thickness for the linear sand dunes (Fig. 6), which agrees well with the result of previous study (Sharratt and Vaddella, 2014). The crust formed by barchan dune sand was too thin to be measured effectively, so we did not establish the relationship between crust thickness and threshold shear velocity. When the crust thickness increased from 2.00 to $14.00 \mathrm{~mm}$, the threshold shear velocity increased from 0.15 to $0.27 \mathrm{~m} / \mathrm{s}$ (increased by $80.00 \%$ ). The thickness of the crust reflects the strength of the cementation of surface particles. The threshold shear velocity of saline sand in this study is smaller than those of the previous studies (Bagnold, 1941; Belly, 1964; Shao and Klose, 2016). This may be due to the different definitions of threshold shear velocity. Since the fluid threshold for natural sediments is a threshold range (Nickling, 1988; Anderson et al., 1991; Pye and Tsoar, 2009), the difference in determining the threshold shear velocity will lead to different statistics. In addition, the method used to determine the initiation of particle motion in this experiment may have better sensitivity.
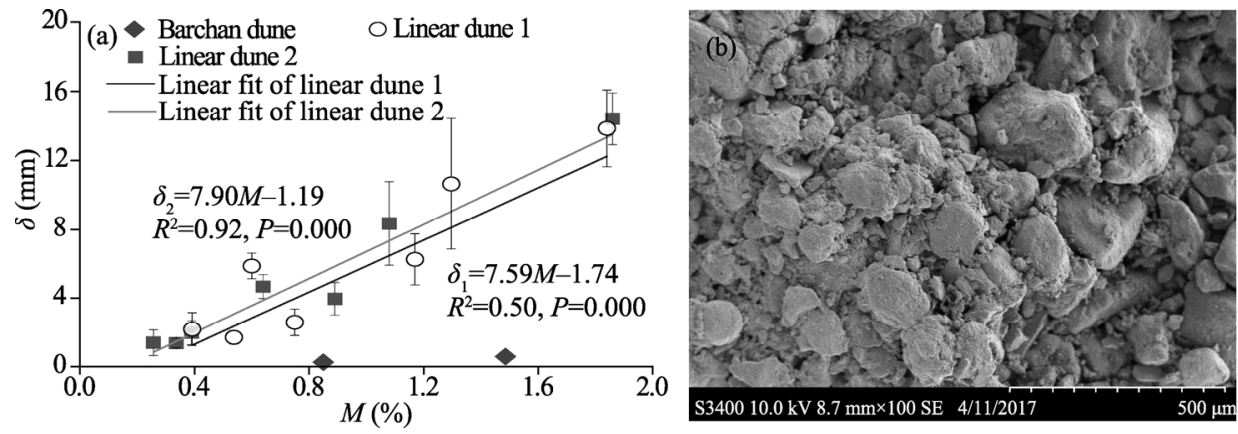

Fig. 5 Relationship between crust thickness $(\delta)$ and original moisture content $(M)$ of saline sand in different sand dunes (a) and scanning electron micrograph of salt crust (b). $\delta_{1}$ and $\delta_{2}$ represent the crust thickness of the linear dune 1 and linear dune 2, respectively.

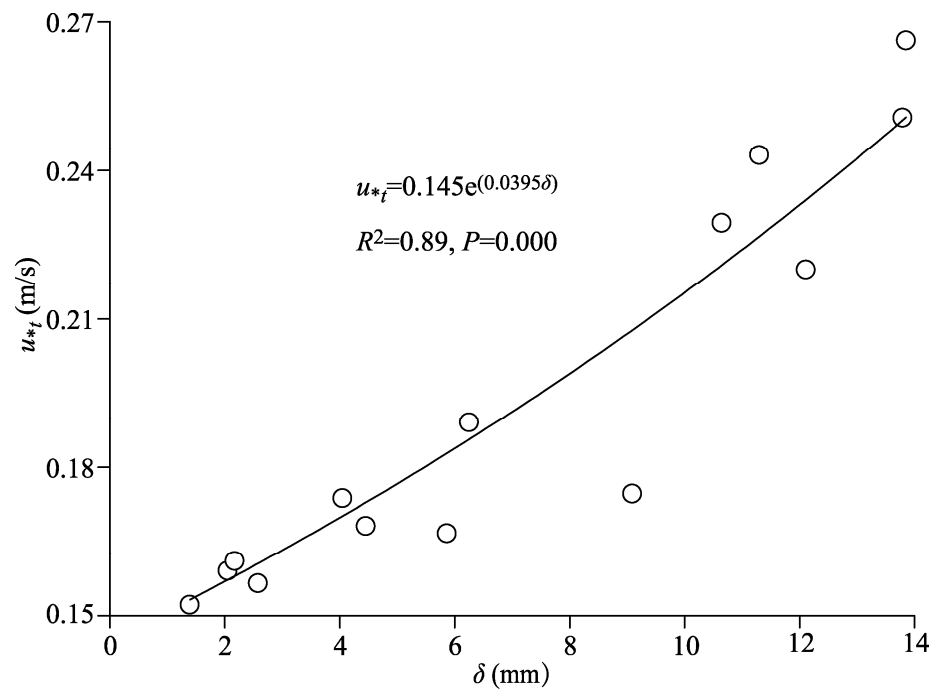

Fig. 6 Exponential relationship between threshold shear velocity $\left(u *_{t}\right)$ and crust thickness $(\delta)$ for the linear dunes

Threshold shear velocity of processed (wet or dewatered) sand $\left(u_{* t r}\right)$ was compared with that of dried loose sand $\left(u_{* t o}\right)$ by calculating the relative threshold shear velocity $\left(U_{* t r} ;\right.$ Eq. 3$)$, which shows the rate of increase in the threshold shear velocity (Dong et al., 2002).

$$
U_{* t r}=u_{* t r} / u_{* t o} \text {. }
$$

As shown in Figure 7, there was a positive linear correlation between relative threshold shear velocity and original moisture content. The threshold shear velocity of saline sand in the barchan 
dune was more decentralized, compared with those in the linear dunes. The higher salt content in the sand could increase water absorption, thus improving the stability of sand. For the two experimental trays with the same original moisture content of saline sand, the relative threshold shear velocity of the dewatered sand was higher than that of the wet sand, and this effect was more pronounced when the salt content was low (Fig. 7). Compared with the wet sand, the increase rate of relative threshold shear velocity of the three dewatered sand samples increased by $32.40 \%$ for the barchan dune, $5.70 \%$ for the linear dune 1 and $5.60 \%$ for the linear dune 2 . The significant difference test of paired samples between the wet and dewatered sand in the barchan dune, linear dune 1 and linear dune 2 showed that the significance values were $0.003,0.150$ and 0.120 , respectively, for the three sand dunes. Although the average particle size of the linear dune 2 was finer than those of the other two sand dunes, its stability was also pronounced with moisture change. This indicates that the effect of interparticle force for the threshold shear velocity of saline sand is more important than that of particle diameter. Our result is consistent with the observation of Nickling (1984), who noted that even relatively low surface salt content can significantly increase the threshold shear velocity. However, it should be pointed out that the dried loose sand does not reduce sand transport because of its salt content. The cohesion of sediment in the Qarhan Desert is the result of a joint effect of salt and water. Deliquescence and desiccation both have significant effects in preventing the initiation of surface particle motion.

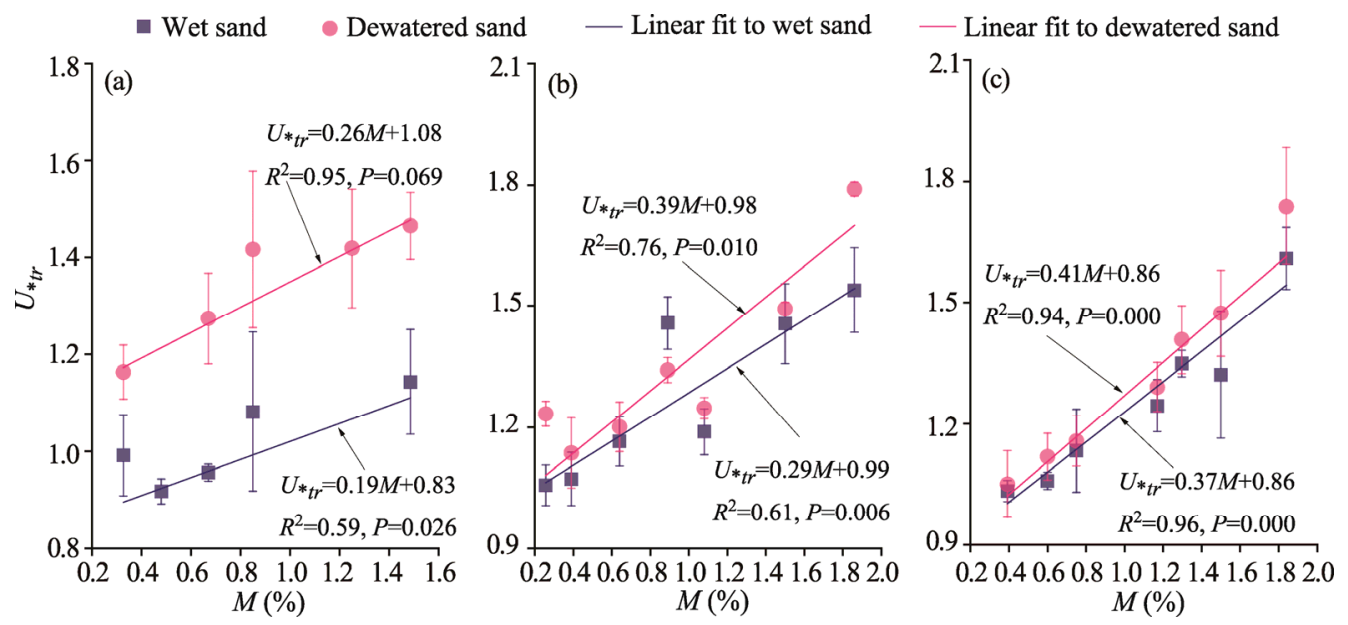

Fig. 7 Relationship between relative threshold shear velocity $\left(U_{* t r}\right)$ and original moisture content $(M)$ of saline sand from the barchan dune (a), linear dune 1 (b) and linear dune 2 (c)

During the experiment, we found that there are two intractable problems that are unavoidable in the wind tunnel experiment. The first problem is that surface moisture continuously evaporates from the wet sand during the experiment. Evaporation can decrease capillary water content and decrease interparticle forces. Variation in temperature and wind speed in the wind tunnel can affect the evaporation rate of water. Therefore, to a certain extent, the initiation of surface particle motion is influenced by evaporation. This phenomenon becomes more acute with lower moisture content of saline sand. Although this problem was previously reported in the research literature, no good solution has been found (Chepil, 1956; Nickling, 1978; Nickling and Ecclestone, 1981; Argaman et al., 2006; Nield et al., 2016). Even though we measured the moisture content of 1-mm depth of saline sand on the surface, which was approximately the total thickness of 5 layers of sand particles $(200.00 \mu \mathrm{m}$ for each layer), the error was still inevitable because surface moisture of wet sand is the key factor in controlling the initiation of particle motion. The second problem is that saline sand absorbs water from the air (Nield et al., 2016). It is difficult to prevent saline soil (solonchak) from deliquescing in an open wind tunnel, and deliquescence increases as the salt content increases. Therefore, the dried sand samples regain water and thus affect the accuracy of the experiment. In this study, we measured the water absorption of saline sand during 
the wind tunnel experiment under the temperature of $10^{\circ} \mathrm{C}$ and relative humidity of $60.00 \%$. Water absorption rates of saline sand for the barchan dune, linear dune 1 and linear dune 2 in 5 min were $0.11 \%, 0.19 \%$ and $0.22 \%$, respectively. So, most of the wind tunnel experiments were completed within 3 min to minimize the range of error due to this absorption.

\subsection{Implication for dune formation and evolution in the Qarhan Desert}

The coexistence of transverse and longitudinal dunes under unidirectional wind regimes in the northern Qarhan Desert has been explained as an effect of cohesive sediment (Rubin and Hesp, 2009). A direct evidence of linear dune formation was that the salt and mud content of the linear dune exceeded that of the barchan dune. However, the TSCS content alone may not completely explain the origin of the linear dunes because the cohesion of sediment results from the combined action of salt and water. Results of our experiment show that the relative threshold shear velocity increased as the increase of moisture content in saline sand, and that the dewatered saline sand became more resistant to the initiation of particle motion. Atmospheric moisture and infiltrated water can enter the interstices of sediments and dissolve fine salt particles to form a viscous solute which coats the particle surfaces. Crystalline crusts formed by air-drying, which are compact and hard. They can significantly increase the threshold shear velocity of saline sand and thus block sand transport. Our results further show the extent to which cohered sediment restricts the sand transport. Quantification of the effect of cohesion on limiting sediment deflation can provide valuable information about aeolian sand transport and aeolian geomorphology in deserts with high salt contents.

\section{Conclusions}

The cohesiveness of sand in the Qarhan Desert is a combination of the effects of salt and water. The formation of crust has undergone a process of deliquescence and desiccation. After adjusting the original moisture content, we found that saline sand with a higher TSCS content is more stable. The threshold shear velocity of saline sand increases exponentially with the increase in crust thickness for the linear sand dunes. There is a positive linear correlation between original moisture content and relative threshold shear velocity. The threshold shear velocity of dewatered sand is greater than that of wet sand with the same original moisture content. The difficulty of controlling the moisture content of saline sand in an open wind tunnel may reduce the accuracy of the threshold shear velocity measurement. Field observation will be a further research alternative. Our results will provide valuable information about the sand transport of highly saline soil in the Qarhan Desert as well as in the other similar desert areas in the world.

\section{Acknowledgements}

This research was funded by the National Natural Science Foundation of China (41601002, 41871008).

\section{References}

Anderson R S, Sørensen M, Willetts B B. 1991. A review of recent progress in our understanding of aeolian sediment transport. In: Barndorff-Nielsen O E, Willetts B B. Aeolian Grain Transport 1 Mechanics. New York: Springer-Verlag Wien, 1-19.

Argaman E, Singer A, Tsoar H. 2006. Erodibility of some crust forming soils/sediments from the Southern Aral Sea Basin as determined in a wind tunnel. Earth Surface Processes and Landforms, 31(1): 47-63.

Bagnold R A. 1941. The Physics of Blown Sand and Desert Dunes. New York: Springer Netherlands, 85-94.

Bao F. 2016. The development environment and processes of aeolian geomorphology around Qaidam Basin Qarhan Salt Lake. PhD Dissertation. Xi'an: Shaanxi Normal University. (in Chinese)

Belly P Y. 1964. Sand movement by wind. In: Technical Memorandum NO.1. US Army Coastal Engineering Research Center, USA.

Belnap J, Gillette D A. 1998. Vulnerability of desert biological soil crusts to wind erosion: the influences of crust development, soil texture, and disturbance. Journal of Arid Environments, 39(2): 133-142.

Brungard C W, Boettinger J L, Hipps L E. 2015. Wind erosion potential of lacustrine and alluvial soils before and after 
disturbance in the eastern Great Basin, USA: Estimating threshold friction velocity using easier-to-measure soil properties. Aeolian Research, 18: 185-203.

Castellanos A. 2005. The relationship between attractive interparticle forces and bulk behaviour in dry and uncharged fine powders. Advances in Physics, 54(4): 263-376.

Chen Y, Tarchitzky J, Brouwer J, et al. 1980. Scanning electron microscope observations on soil crusts and their formation. Soil Science, 130(1): 49-55.

Chepil W S. 1956. Influence of moisture on erodibility of soil by wind. Soil Science Society of America Journal, 20(2): 288292.

Chepil W S. 1958. Soil Conditions that Influence Wind Erosion. Washington: Technical Bulletins, 1-38.

Davidson-Arnott R G D, Yang Y, Ollerhead J, et al. 2008. The effects of surface moisture on aeolian sediment transport threshold and mass flux on a beach. Earth Surface Processes and Landforms, 33(1): 55-74.

Dong Z B, Liu X P, Wang X M. 2002. Wind initiation thresholds of the moistened sands. Geophysical Research Letters, 29(12): 1585, doi: 10.1029/2001GL013128.

Dong Z B, Wang H T, Liu X P, et al. 2004. The blown sand flux over a sandy surface: a wind tunnel investigation on the fetch effect. Geomorphology, 57(1-2): 117-127.

Dong Z B, Hu G Y, Qian G Q, et al. 2017. High-altitude aeolian research on the Tibetan Plateau. Reviews of Geophysics, 55(4): 864-901.

Ellis J T, Sherman D J. 2013. Fundamentals of aeolian sediment transport: Wind-blown sand. In: Shroder J F. Treatise on Geomorphology. San Diego: Academic Press, 85-108.

Folk R L, Ward W C. 1957. Brazos river bar: a study in the significance of grain size parameters. Journal of Sedimentary Research, 27(1): 3-26.

Gillette D A, Adams J, Muhs D, et al. 1982. Threshold friction velocities and rupture moduli for crusted desert soils for the input of soil particles into the air. Journal of Geophysical Research, 87(C11): 9003-9015.

Gomes L, Arrúe J L, López M V, et al. 2003. Wind erosion in a semiarid agricultural area of Spain: the WELSONS project. Catena, 52(3-4): 235-256.

Ishizuka M, Mikami M, Leys J, et al. 2008. Effects of soil moisture and dried raindroplet crust on saltation and dust emission. Journal of Geophysical Research, 113(D24): D24212, doi: 10.1029/2008JD009955.

Kok J F, Parteli E J R, Michaels T I, et al. 2012. The physics of wind-blown sand and dust. Reports on Progress in Physics, 75(10): 106901, doi: 10.1088/0034-4885/75/10/106901.

Leys J F, Eldridge D J. 1998. Influence of cryptogamic crust disturbance to wind erosion on sand and loam rangeland soils. Earth Surface Processes and Landforms, 23(11): 963-974.

Li J Y, Dong Z B, Zhang Z C, et al. 2015. Grain-size characteristics of linear dunes on the northern margin of Qarhan Salt Lake, northwestern China. Journal of Arid Land, 7(4): 438-449.

Li J Y, Dong Z B, Qian G Q, et al. 2016. Pattern analysis of a linear dune field on the northern margin of Qarhan Salt Lake, northwestern China. Journal of Arid Land, 8(5): 670-680.

Martin R L, Kok J F. 2017. Field measurements demonstrate distinct initiation and cessation thresholds governing aeolian sediment transport flux. [2017-07-31]. https://ui.adsabs.harvard.edu/abs/2016arXiv161010059M.

Musick H B, Trujillo S M, Truman C R, et al. 1996. Wind-tunnel modelling of the influence of vegetation structure on saltation threshold. Earth Surface Processes and Landforms, 21(7): 589-605.

Namikas S L, Sherman D J. 1995. A review of the effects of surface moisture content on aeolian sand transport. In: Tchakerian V P. Desert Aeolian Processes. Dordrecht: Springer Science+Business Media, 269-293.

Nickling W G. 1978. Eolian sediment transport during dust storms: Slims River Valley, Yukon Territory. Canadian Journal of Earth Sciences, 15(7): 1069-1084.

Nickling W G, Ecclestone M. 1981. The effects of soluble salts on the threshold shear velocity of fine sand. Sedimentology, 28(4): 505-510.

Nickling W G. 1984. The stabilizing role of bonding agents on the entrainment of sediment by wind. Sedimentology, 31(1): 111-117.

Nickling W G. 1988. The initiation of particle movement by wind. Sedimentology, 35(3): 499-511.

Nickling W G, Neuman C M. 2009. Aeolian sediment transport. In: Abrahams A D, Parsons A J. Geomorphology of Desert Environments. Dordrecht: Springer Science+Business Media, 517-555.

Nield J M, Neuman C M, O'Brien P, et al. 2016. Evaporative sodium salt crust development and its wind tunnel derived transport dynamics under variable climatic conditions. Aeolian Research, 23: 51-62.

Orlovsky N, Orlovsky L, Yang Y, et al. 2003. Salt duststorms of Central Asia since 1960s. Journal of Desert Research, 23(1): 18-27. (in Chinese)

Pullen A, Kapp P, McCallister A T, et al. 2011. Qaidam Basin and northern Tibetan Plateau as dust sources for the Chinese Loess Plateau and paleoclimatic implications. Geology, 39(11): 1031-1034. 
Pye K. 1980. Beach salcrete and eolian sand transport: evidence from north Queensland. Journal of Sedimentary Research, 50(1): 257-261.

Pye K, Tsoar H. 2009. Aeolian Sand and Sand Dunes. Berlin Heidelberg: Springer Science+Business Media, 99-113.

Raffaele L, Bruno L, Pellerey F, et al. 2016. Windblown sand saltation: A statistical approach to fluid threshold shear velocity. Aeolian Research, 23: 79-91.

Raffaele L, Bruno L, Wiggs G F S. 2018. Uncertainty propagation in aeolian processes: From threshold shear velocity to sand transport rate. Geomorphology, 301: 28-38.

Ravi S, Zobeck T M, Over T M, et al. 2006. On the effect of moisture bonding forces in air-dry soils on threshold friction velocity of wind erosion. Sedimentology, 53(3): 597-609.

Rohrmann A, Heermance R, Kapp P, et al. 2013. Wind as the primary driver of erosion in the Qaidam Basin, China. Earth and Planetary Science Letters, 374(4): 1-10.

Rubin D M, Hesp P A. 2009. Multiple origins of linear dunes on Earth and Titan. Nature Geoscience, 3(2): $653-658$.

Rubin D M, Rubin A M. 2013. Origin and lateral migration of linear dunes in the Qaidam Basin of NW China revealed by dune sediments, internal structures, and optically stimulated luminescence ages, with implications for linear dunes on Titan: Discussion. Geological Society of America Bulletin, 125(11-12): 1943-1946.

Shao Y P, Lu H. 2000. A simple expression for wind erosion threshold friction velocity. Journal of Geophysical Research, 105(D17): 22437-22443.

Shao Y P. 2008. Physics and Modelling of Wind Erosion. Dordrecht: Springer Science+Business Media, 134-145.

Shao Y P, Klose M. 2016. A note on the stochastic nature of particle cohesive force and implications to threshold friction velocity for aerodynamic dust entrainment. Aeolian Research, 22: 123-125.

Sharratt B S, Vaddella V. 2014. Threshold friction velocity of crusted windblown soils in the Columbia Plateau. Aeolian Research, 15: 227-234.

Sherman D J, Jackson D W T, Namikas S L, et al. 1998. Wind-blown sand on beaches: an evaluation of models. Geomorphology, 22: 113-133.

Udden J A. 1914. Mechanical composition of clastic sediments. Geological Society of America Bulletin, 25(1): 655-744.

Wang X M, Hua T, Zhang C X, et al. 2013. Salts in the clay playas of China's arid regions: gone with the wind. Environmental Earth Sciences, 68(3): 623-631.

Wentworth C K. 1922. A scale of grade and class terms for clastic sediments. Journal of Geology, 30(5): 377-392.

Wilkinson R H. 1983. A method for evaluating statistical errors associated with logarithmic velocity profiles. Geo-Marine Letters, 3(1): 49-52.

Williams J J, Butterfield G R, Clark D G. 1990. Rates of aerodynamic entrainment in a developing boundary layer. Sedimentology, 37(6): 1039-1048.

Wolfe S A, Hugenholtz C H. 2009. Barchan dunes stabilized under recent climate warming on the northern Great Plains. Geology, 37(11): 1039-1042.

Xi X, Sokolik I N. 2015. Seasonal dynamics of threshold friction velocity and dust emission in Central Asia. Journal of Geophysical Research Atmospheres, 120(4): 1536-1564.

Xiao L, Wang J, Dang Y, et al. 2017. A new terrestrial analogue site for Mars research: The Qaidam Basin, Tibetan Plateau (NW China). Earth-Science Reviews, 164: 84-101.

Yan Y C, Wu L H, Xin X P, et al. 2015. How rain-formed soil crust affects wind erosion in a semi-arid steppe in northern China. Geoderma, 249-250: 79-86.

Zhang X Y, Gong S L, Zhao T L, et al. 2003. Sources of Asian dust and role of climate change versus desertification in Asian dust emission. Geophysical Research Letters, 30(24): 2272, doi: 10.1029/2003GL018206.

Zhang Z, Dong Z, Zhao A, et al. 2008. The effect of restored microbiotic crusts on erosion of soil from a desert area in China. Journal of Arid Environments, 72(5): 710-721.

Zhang Z C, Dong Z B, Li J Y, et al. 2016. Implications of surface properties for dust emission from gravel deserts (gobis) in the Hexi Corridor. Geoderma, 268: 69-77.

Zhang Z C, Dong Z B, Qian G Q, et al. 2018. Formation and development of dunes in the northern Qarhan Desert, central Qaidam Basin, China. Geological Journal, 53(3): 1123-1134.

Zhou J X, Zhu Y, Yuan C Q. 2012. Origin and lateral migration of linear dunes in the Qaidam Basin of NW China revealed by dune sediments, internal structures, and optically stimulated luminescence ages, with implications for linear dunes on Titan. Geological Society of America Bulletin, 124(7-8): 1147-1154.

Zimon A D. 1982. Adhesion of Dust and Powder. Boston: Springer Science+Business Media, 1-36.

Zobeck T M. 1991. Soil properties affecting wind erosion. Journal of Soil and Water Conservation, 46(2): 112-118. 